Article

\title{
Optimized Cool Coatings as a Strategy to Improve Urban Equivalent Albedo at Various Latitudes
}

\author{
Mattia Manni ${ }^{1,2, *(D)}$ and Andrea Nicolini ${ }^{1,2}$ (D) \\ 1 CIRIAF-Interuniversity Research Center on Pollution and Environment "Mauro Felli", 06125 Perugia, Italy \\ 2 Department of Engineering, University of Perugia, 06123 Perugia, Italy; andrea.nicolini@unipg.it \\ * Correspondence: mattia.manni@unipg.it
}

Citation: Manni, M.; Nicolini, A.

Optimized Cool Coatings as a

Strategy to Improve Urban

Equivalent Albedo at Various

Latitudes. Atmosphere 2021, 12, 1335.

https://doi.org/10.3390/

atmos12101335

Academic Editors: Yongming Han,

Nanjun Chen and Merja Tölle

Received: 15 September 2021

Accepted: 9 October 2021

Published: 13 October 2021

Publisher's Note: MDPI stays neutral with regard to jurisdictional claims in published maps and institutional affiliations.

\begin{abstract}
This research study aimed to investigate the influences of angular-selective retro-reflective (AS-RR) and retro-reflective (RR) materials on the urban equivalent albedo $\left(\alpha_{\mathrm{eq}}\right)$. Full ray tracing solar analyses were conducted through the Monte Carlo-based numerical model validated in a previous work. Different geometry scenarios with different patterns of urban density were modelled. AS-RR and RR materials were alternately applied to the street and to the most irradiated façade. AS-RR materials were proposed to enhance the $\alpha_{\mathrm{eq}}$ of the urban environment particularly during summer. Solar analyses were reiterated for three latitudes (i.e., Oslo, Milan, Cairo). RR pavements and façades were capable of increasing the $\alpha_{\mathrm{eq}}$ throughout the year. However, implementing an angular-selective behavior allowed for a reduction of the mitigation potential of RR materials during the winter season. In their best application, RR and AS-RR materials enabled higher $\alpha_{\mathrm{eq}}$ in summer (122\%) with negligible effects during the winter (7\%). Finally, the study highlighted the need for exploiting numerical models capable of conducting full ray tracing solar analyses when investigating materials whose optical properties depend on the angle of incidence of the sunrays (such as RR materials).
\end{abstract}

Keywords: retro-reflective materials; solar analyses; urban canyon model

\section{Introduction}

Urban overheating results from a synergistic combination of local and global climate change phenomena. The most documented issue associated with that is the urban heat island (UHI) effect. This is caused by a lack of permeable and vegetated surfaces, the materials used in the built environment, anthropogenic heat, worsened ventilation within urban canopies, and higher pollutants concentration in the atmosphere [1-4]. The UHI has been observed in urban districts from the 20th century, and it has been largely documented and discussed in the literature [5-9]. Anti-cyclonic conditions related to low wind speed, and clear sky were found to strongly contribute to increased UHI magnitude. Whereas, precipitation decreases this due to the increment of the thermal admittance of rural areas [10].

Extensive monitoring has documented increased air temperatures in more than 450 major municipalities throughout the world [11-14]. The amplitude of the overheating of these cities depends on urban patterns, landscape, and specifics of the regional climate [15-18]. In addition, a reduced number of trees and permeable surfaces, higher production of anthropogenic heat, and properties of the materials used for outdoor pavements and building fabrics contribute to the increase of local thermal stress in big cities $[1-4,16,19]$. A comprehensive analysis on 100 Asian and Australian cities revealed that the local effects of UHI are remarkable by presenting a maximum amplitude close to $5{ }^{\circ} \mathrm{C}$, but it may vary up to $10^{\circ} \mathrm{C}[10]$.

Within this framework, evapotranspiration from plants [20,21], blue infrastructures (i.e., bodies of water) [22], energy storage potential [23,24], and cool materials (i.e., highly reflective coatings) $[25,26]$ were identified by numerous studies as effective strategies to 
mitigate the UHI effects. In particular, highly reflective (HR) coatings were found to be capable of modifying the urban microclimate by determining surface and air temperatures, altering both the energy demand for cooling and electricity energy peaks, and influencing indoor thermal comfort conditions [27,28]. Nonetheless, their effectiveness depends on solar accessibility, which is negatively influenced by factors, such as urban density and the window-to-wall ratio of façades [29]. Highly reflective materials also lead to reduced solar energy gains through the building's envelope during winter and increase the energy demand for heating whereas a progressive worsening of their optical properties can be observed due to aging, pollution, and weathering effects [30]. Moreover, the HR coatings may contribute to exacerbating the UHI phenomenon by increasing multiple and mutual inter-buildings reflection events, thus reducing the amount of solar radiation reflected out of the urban canopy with negative effects on pedestrians' thermal comfort [31].

To overcome this issue, retro-reflective (RR) materials were proposed as the next generation of cool coatings [32-34]. Indeed, they can minimize inter-buildings effects by orienting backward (out of the urban canopy) the reflected solar irradiation. Commercial films, realized with prism-array structures, capsule-lens, and bead-embedded layers, were tested to demonstrate their effectiveness in mitigating UHI [32,35]. The results highlighted that the building energy demand can be reduced by up to $10 \%$ when RR materials are applied to urban surfaces in place of traditional cool materials (e.g., diffuse HR materials) [36].

Despite the proven advantages of the different RR technologies, there are still some aspects that need to be addressed to fully enable the potentials of these coating systems. RR surfaces may contribute to increased glare-related issues and light pollution, while reducing solar loads in winter. Hence, Sakai et al. [37] and Manni et al. [38] implemented an angular-selective behavior on RR materials to enhance their effectiveness. The concept behind the angular-selective retro-reflective (AS-RR) materials is to have surface treatments that are responsive to the solar radiation stimulus and are capable of modifying their optical properties depending the angle of incidence of the sunrays (Figure 1). Methodologies to define their angular range of activation were investigated by Manni et al. [38]. Numerical analyses estimated a reduction of solar irradiation absorbed by the façade of up to $8 \%$ due to the application of AS-RR instead of conventional coatings [39,40].

a.

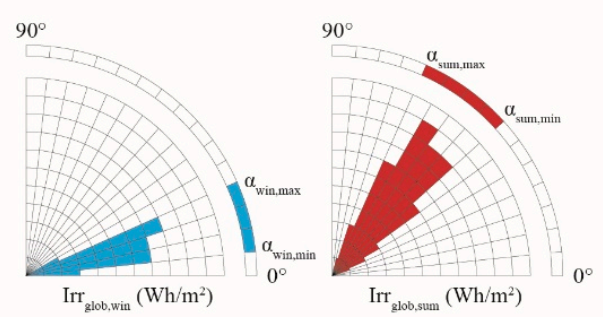

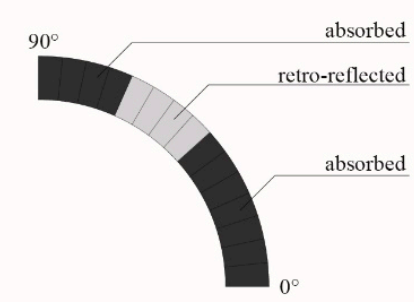

b.

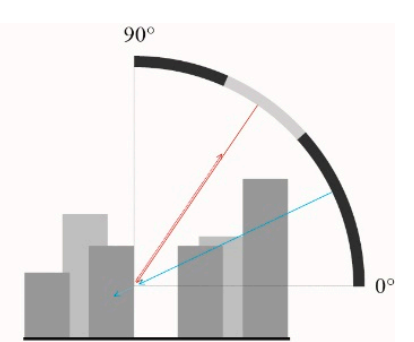

c.

Figure 1. Conceptualization process and functioning of AS-RR materials. (a) Angular distribution of the solar irradiation estimated for a generic latitude of Continental Europe in the summer and winter season. (b) Absorption/retro-reflection pattern implemented for angular-selective retro-reflective (AS-RR) materials. (c) Angular-selective behavior of the AS-RR materials applied to the façade in a generic street corridor.

This study investigated the influences on the urban equivalent albedo of RR and AS-RR materials when applied on the street ground and the south-exposed façade, which is the most irradiated surface according to Lobaccaro et al. [41]. This study aimed to contribute to knowledge generation about the effects of RR and AS-RR materials on urban microclimates. Solar analyses were conducted through an urban canopy model (UCM) by varying the density pattern as well as the city latitude.

This work moves from the study carried out by Manni et al. [42] in which the AS$\mathrm{RR}$ materials were conceptualized and developed, with the aim of defining guidelines about their exploitation as innovative urban coatings through the Monte Carlo-based numerical model validated by Manni et al. [39]. The Monte Carlo-based numerical model 
was chosen due to its high degree of accessibility: users can directly interact and modify all the parameters defining the physical criteria that reflection events are based on (i.e., ray exit angles, light scattering pattern, material optical properties) to assess inter-buildings short-wave solar reflections within the computational domain. Other software and UCMs that exist in the literature were not considered since they showed some simplifications in the solar ray-tracing approach. In particular, surfaces were exclusively modelled as isotropic reflectors by Martilli et al. [43] and Masson et al. [44] and as Lambertian diffuse surfaces by Kusaka et al. [45] and Wang et al. [46]. Similarly, software commonly exploited for conducting solar analysis, such as Diva for Rhino, Ladybug, and Honeybee, do not permit simulation of retro-reflective coatings [39].

\section{Materials and Methods}

\subsection{Workflow}

The workflow followed in this research study was organized in three stages: from the solar analyses to the data post-processing, and to the definition of guidelines about the exploitation of RR and AS-RR materials as new urban coatings. A preliminary stage that concerns the materials characterization and the development of the material virtual clones can be also considered as part of this workflow, although it was carried out and described by Manni et al. [40].

During the first stage, solar analyses were conducted. Input parameters concerned the virtual clones of the materials, the boundary conditions (i.e., location, climate variables), and the system variables (i.e., number of ambient bounces, number of finite elements, number of events). Up to 15 urban canopy scenarios were modelled by varying the exploited materials and the density patterns. Solar analyses were reiterated for each latitude (i.e., Oslo, Milan, Cairo) as well as for summer and winter conditions (two days were selected as representative of the two seasons). The solar radiation reflected out of the urban corridor was estimated with an hourly time step throughout the selected days. In particular, this solar radiation amount was assessed by the numerical model as the solar irradiation impinging on a horizontal surface, which simulates the skydome, and from which the sunrays entered the street corridor.

In the second stage, outcomes were post-processed to calculate the equivalent albedo $\left(\alpha_{\mathrm{eq}}\right)$ for each scenario. The $\alpha_{\mathrm{eq}}$ was estimated on a daily basis. It is defined as the ratio of radiosity to irradiance received by a surface. While the reflection coefficient is calculated for a single angle of incidence, albedo is the directional integration of reflectance over all solar angles in a given period. Equation (1) was used to estimate the $\alpha_{\text {eq: }}$ :

$$
\alpha_{\mathrm{eq}}=\frac{\operatorname{Irr}_{\text {refl,out }}}{\operatorname{Irr}_{\text {glob,hor }}}
$$

where $\operatorname{Irr}_{\text {refl, out }}$ is the amount of shortwave solar radiation reflected out of the urban canopy and $\operatorname{Irr}_{\text {glob,hor }}$ is the amount of shortwave solar radiation incident on an unobstructed horizontal surface (Figure 2).

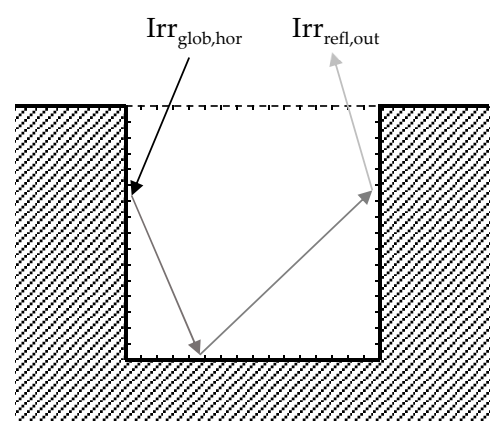

Figure 2. Section view of the urban canyon in which the solar irradiation entering the canyon environment and the solar radiation reflected out are represented along to multiple reflections. 
Finally, these data were post-processed in stage three to calculate the percent variations $(\Delta \%)$ in the equivalent Albedo from the baseline scenario for summer $(\Delta \%$,sum $)$ and winter seasons $(\Delta \%$,win $)$. Equation (2) was used to estimate the $\Delta \%$ :

$$
\Delta \%=\frac{\alpha_{\text {eq,enh }}-\alpha_{\text {eq,ref }}}{\alpha_{\text {eq, ref }}} \cdot 100
$$

where $\alpha_{\text {eq,enh }}$ and $\alpha_{\text {eq,ref }}$ are the equivalent Albedo values estimated for the enhanced scenario and the reference case, respectively.

Following this, such percentages were compared and discussed to identify guidelines about the application of RR and AS-RR materials to building façades and street paving.

\subsection{Virtual Clone Development}

The virtual clones implemented by Manni et al. [40] were utilized in this study. The RR materials were characterized and modelled; then, the angular ranges of activation identified by Manni et al. [38] for each climate zone were applied to these. In this manuscript, data used for modelling the virtual clone of RR materials are reported, while a more complete description of the protocols applied for the characterization, and the characterization results themselves can be found in the study by Castellani et al. [47].

Barium titanate glass microspheres were selected among the RR materials characterized by Castellani et al. [47]. They show the best performance as retro-reflectors when no significant chromatic alteration of the treated surface appears. In fact, higher solar reflectance values can be observed in RR materials, which alter the original surface's color into a metallic tone. However, such microspheres were found to be capable of implementing an RR behavior on the surface while enhancing the surface global reflectance up to around 0.4. Measured quantities were post-processed to determine the reflection coefficients for the Lambertian diffusively reflected, the specular reflected, and the retro-reflected components, and the absorption coefficient for each angle of incidence of the sunrays. These parameters, which describe the material optical behavior in the numerical model, are reported in Figure 3.

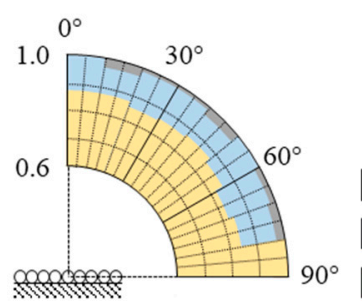

Specular reflection coefficient

Retro-reflection coefficient

Diffuse reflection coefficient

Figure 3. Coefficients describing the material reflective properties depending on the angle of incidence of the solar irradiation.

When it comes to the AS-RR coatings, these exhibited a selective behavior activated by the angle of incidence of sunrays. A specific angular range of activation of the RR properties was set for each surface exposure (i.e., vertical, horizontal) as well as for each latitude (i.e., northern zone, central zone, southern zone), in accordance with the guidelines identified by Manni et al. [38]. AS-RR materials behave as retro-reflectors as long as the incident angle falls within the angular range of activation while presenting a Lambertian diffuse behavior outside the angular range (Figure 4). 

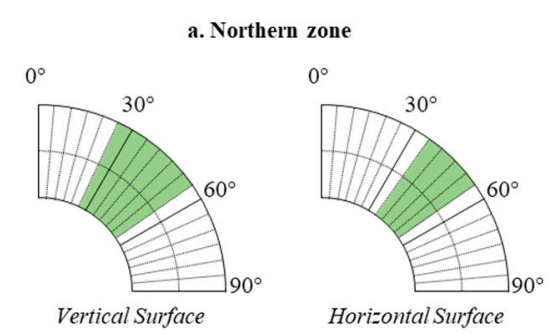

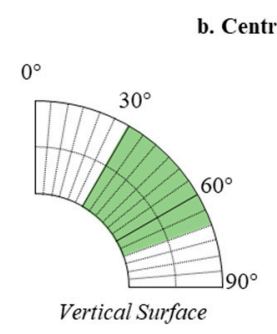

Angular range of activation of retro-reflective properties $0^{\circ}$

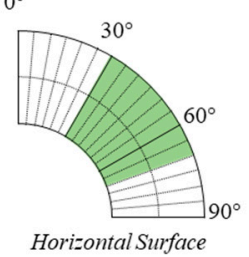

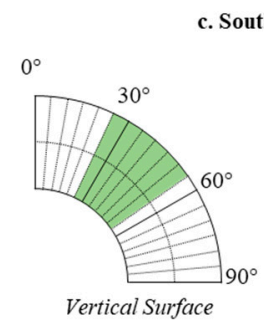

$0^{\circ}$

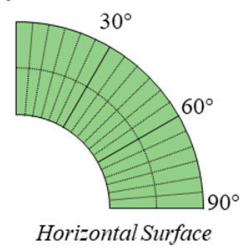

Figure 4. Angular ranges of activation defined in Ref. [38] for a horizontal and vertical surface, and for each climate zone.

\subsection{Full-Ray Tracing Algorithm}

The solar analyses were performed through a Matlab routine, which is described and experimentally validated by Manni et al. [39]. The numerical model and its full-ray tracing routine are based on a Monte Carlo approach that permitted estimation of the solar irradiation collected by each finite element of the skydome as the probability that sunrays impinge on this surface according to the input data. Similarly, the reflection and the absorption phenomena that take place when sunrays hit the urban canyon's surfaces were assessed in terms of probability. An energy amount is assigned to each sunray as high as the ratio between the solar irradiation entering the urban canyon environment and the number of simulated sunrays. In terms of the geometrical configuration, a single-layer canopy model was implemented. The investigated scenario consisted of a two-dimensional, symmetrical street canyon with infinite length and customizable dimensions (building's height $(\mathrm{H})$ and street's width $(\mathrm{W}))$. The radiation assessment was a three-dimensional one as it also considered the variation of the sun azimuth throughout the day in addition to the canyon's orientation. The proposed model aims at simulating solar reflections within the street environment by reliably reproducing the optical properties of the coatings. It allows estimation of the effectiveness of different UHI mitigation strategies in various scenarios during remarkable moments of the year. Hence, the model is particularly useful in preliminary design stages when several alternative configurations, which are not yet completely defined, are compared to select the best one.

Input parameters required by the numerical model concern:

1. UC geometrical features, such as the orientation, the buildings' height, and the UC height-to-width ratio (street's width is calculated from these);

2. Optical properties of the urban surface, such as the absorption and reflection coefficients;

3. Boundary conditions, such as global solar irradiation, sun position, and clearness index (diffuse and direct irradiation are calculated from these);

4. Simulation variables, such as the resolution of the grid simulating the skydome (number of finite elements), the number of sunrays entering the UC through the top surface (number of events), and the maximum number of sunrays reflections that can be assessed in the ray tracing (ambient bounces number).

In particular, simulation variables were set to minimize the computational time while maintaining the results' uncertainty below a 5.0\% threshold. The amount of ambient bounces (i.e., sunrays reflections) considered in the ray-tracing analyses for each sunray before the cutoff was set to equal six. The number of cells in which the skydome and the UC surfaces were divided was determined to guarantee an adequate discretization of the results (the distance between two consecutive test points is around one meter). Finally, the number of events was as high as $10^{6}$ events. Such settings allowed the solar analyses to be conducted with an around 3.0\% uncertainty [39].

\subsection{Investigated Scenarios}

Each urban canyon configuration was univocally defined by a combination of the orientation, aspect ratio, and material properties. The west-east orientation was evaluated since it represents the one showing the greatest difference in solar accessibility between 
the two façades [42]. Three different patterns of urban density, such as low, middle, and high density, were explored by varying the height-to-width ratio from 0.5 to 1.0 , and to 2.0 . The urban canyon geometry was two-dimensional and simulated the conditions observed within infinitely long street corridors in which the boundary effects of the extremes of the UC are neglected. The dimensions (reported as the building's height by the street's width) were $16 \mathrm{~m}$ by $8 \mathrm{~m}$ in case of a $2.0 \mathrm{H} / \mathrm{W}, 16 \mathrm{~m}$ by $16 \mathrm{~m}$ if H/W equaled 1.0, and $16 \mathrm{~m}$ by $32 \mathrm{~m}$ when $\mathrm{H} / \mathrm{W}$ was 0.5 . The height of the buildings was kept constant throughout the study.

When it comes to the material patterns, traditional diffuse materials, such as asphalt (0.20 reflection coefficient) and brown paint ( 0.35 reflection coefficient), were used for the "reference case" and applied to the street and façade surfaces. Differently from the reference case, RR and AS-RR materials were alternately applied to the south-exposed façade or to the street paving. In total, up to five material patterns were analyzed for each UC geometry (Table 1). Urban canyon surfaces were considered to have constant and homogenous optical properties, which varied depending on the case studies.

Table 1. Summary of the material patterns that were investigated for each UC geometry.

\begin{tabular}{cccc}
\hline \multirow{2}{*}{$\begin{array}{c}\text { Investigated } \\
\text { Scenarios }\end{array}$} & \multicolumn{3}{c}{ Applied Materials } \\
\cline { 2 - 4 } & South-Exposed Façade & Street Ground & North-Exposed Façade \\
\hline Reference case & Brown painting & Asphalt & Brown painting \\
Case a & Brown painting & RR from the Literature & Brown painting \\
Case b & Brown painting & AS-RR & Brown painting \\
Case c & RR from the Literature & Asphalt & Brown painting \\
Case d & AS-RR & Asphalt & Brown painting \\
\hline
\end{tabular}

Three city locations were chosen as representative of three different climate zones: Oslo $\left(59^{\circ} 55^{\prime} 0^{\prime \prime} \mathrm{N}, 10^{\circ} 45^{\prime} 0^{\prime \prime} \mathrm{E}\right)$ for the northern zone, Milan $\left(45^{\circ} 28^{\prime} 0^{\prime \prime} \mathrm{N}, 9^{\circ} 12^{\prime} 0^{\prime \prime} \mathrm{E}\right)$ for the central zone, and Cairo $\left(30^{\circ} 2^{\prime} 39^{\prime \prime} \mathrm{N}, 31^{\circ} 14^{\prime} 8^{\prime \prime} \mathrm{E}\right)$ for the southern zone. Data about solar irradiation were obtained from statistic-based weather data files. Further, 21 June and 21 December were considered as representative of summer and winter conditions, respectively. Solar analyses were conducted with an hourly time step throughout the day, and results were expressed in watt-hour per square meter. The daylight accessibility of an unobstructed horizontal surface was evaluated for determining the duration of the day at each latitude and for each season (Table 2 and Figure 5).

Table 2. Sunrise and sunset hours for the investigated latitudes.

\begin{tabular}{ccccc}
\hline & \multicolumn{2}{c}{ 21 June } & \multicolumn{2}{c}{ 21 December } \\
\hline & Sunrise & Sunset & Sunrise & Sunset \\
\hline Oslo & $5: 00$ a.m. & $7: 00$ p.m. & $10: 00$ a.m. & $1: 00$ p.m. \\
Milan & $5: 00$ a.m. & $6: 00$ a.m. & $9: 00$ a.m. & $3: 00$ p.m. \\
Cairo & $6: 00$ a.m. & $5: 00$ p.m. & 8:00 a.m. & $4: 00$ p.m. \\
\hline
\end{tabular}
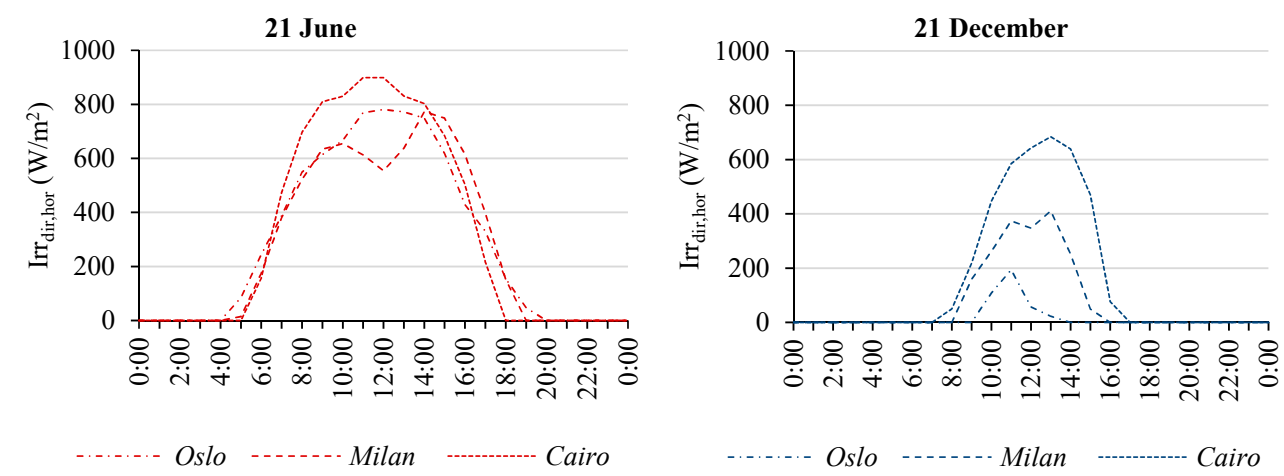

Figure 5. Hourly distribution of $\operatorname{Irr}_{\text {dir,hor }}$ over the 21 June and the 21 December. 
When it comes to the solar accessibility of façade and street surfaces within the investigated UC configurations, the amount of global solar irradiation ( $\operatorname{Irr}_{\text {glob }}$ ) impinging on each surface is reported in Figure 6 (summer season) and Figure 7 (winter season) for Oslo, Milan, and Cairo. The south-exposed façade is always the most irradiated although such a gap in terms of $\operatorname{Irr}_{\text {glob }}$ raises moving from Cairo to Oslo during the summer (Figure 6). Conversely, differences in solar global irradiation between the two façades are reduced moving from Cairo to Oslo during the winter (Figure 7). Finally, the street surface is more irradiated in the southern zone than in the northern zone during both the summer and the winter.
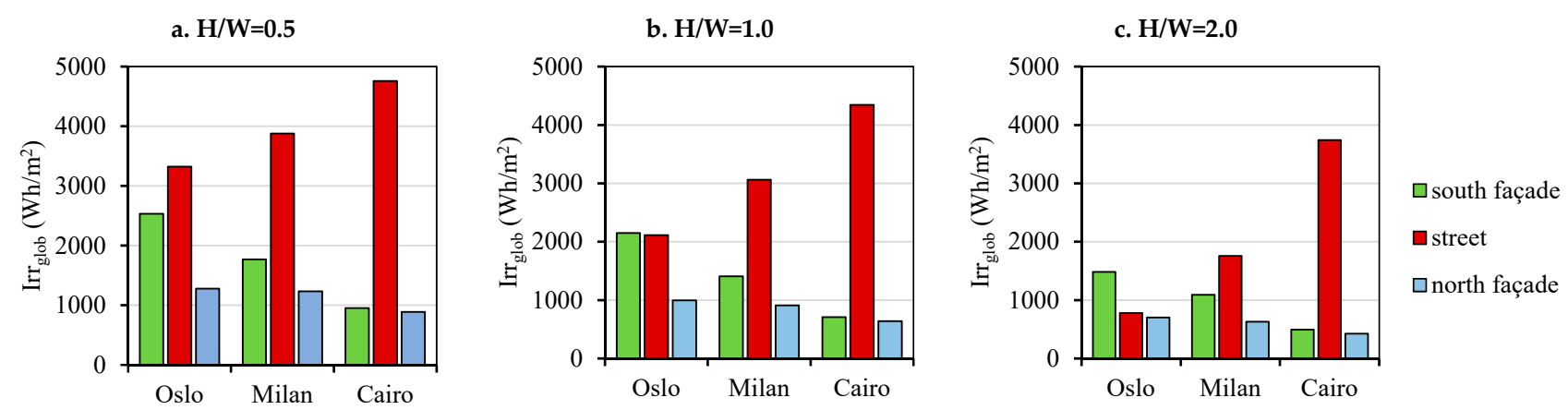

Figure 6. From the left: (a) Irr ${ }_{\text {glob }}$ impinging on urban surfaces for the selected latitudes in low-density UC, during the summer season. (b) Irr $_{\text {glob }}$ impinging on urban surfaces for the selected latitudes in medium-density UC, during the summer

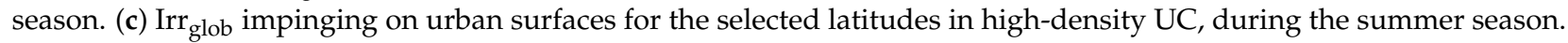

a. $\mathrm{H} / \mathrm{W}=0.5$

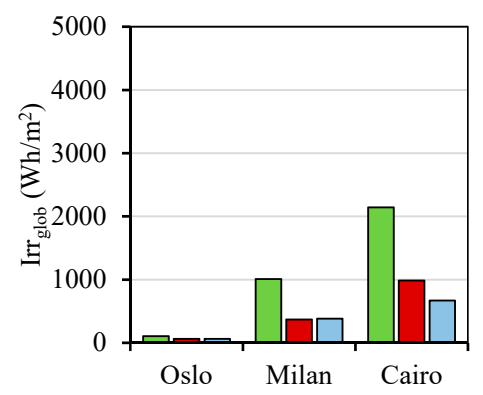

b. $\mathrm{H} / \mathrm{W}=1.0$

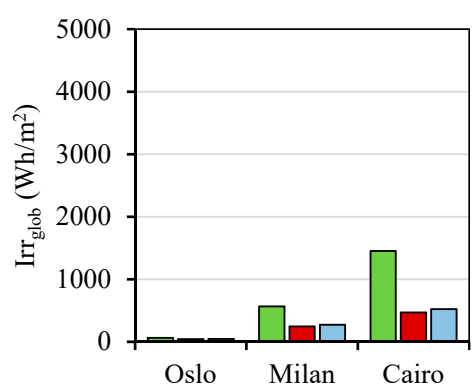

c. $\mathrm{H} / \mathrm{W}=\mathbf{2 . 0}$

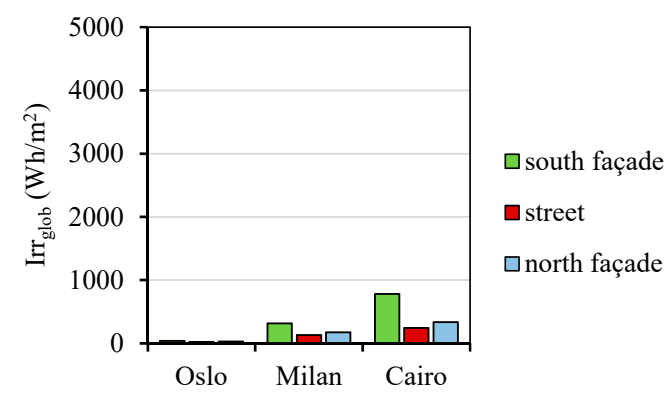

Figure 7. From the left: (a) Irr $_{\text {glob }}$ impinging on urban surfaces for the selected latitudes in low-density UC, during the winter season. (b) Irr $_{\text {glob }}$ impinging on urban surfaces for the selected latitudes in medium-density UC, during the winter season. (c) $\operatorname{Irr}_{\text {glob }}$ impinging on urban surfaces for the selected latitudes in high-density UC, during the winter season.

\section{Results and Discussion}

\subsection{Equivalent Albedo in the Reference Case Scenario}

The results from the solar analyses carried out for the reference case demonstrated that the highest $\alpha_{\mathrm{eq}}$ values were typically observed for the UC scenarios characterized by a low-density pattern. Variations among the $\alpha_{\text {eq }}$ calculated for the different climate zones during summer were more evident in medium- and high-density UC. In the other cases, when the same density was considered, the $\alpha_{\text {eq }}$ amounts were similar. Moreover, the estimated $\alpha_{\mathrm{eq}}$ values turned out to be higher during winter than during summer due to the fact that sunrays impinged prevalently on buildings' façades during winter. In fact, façades are characterized by a higher solar reflectance than street surface.

A complete overview of the estimated $\alpha_{\text {eq }}$ quantities (for each climate zone and every aspect ratio) is reported in Figure 8. 

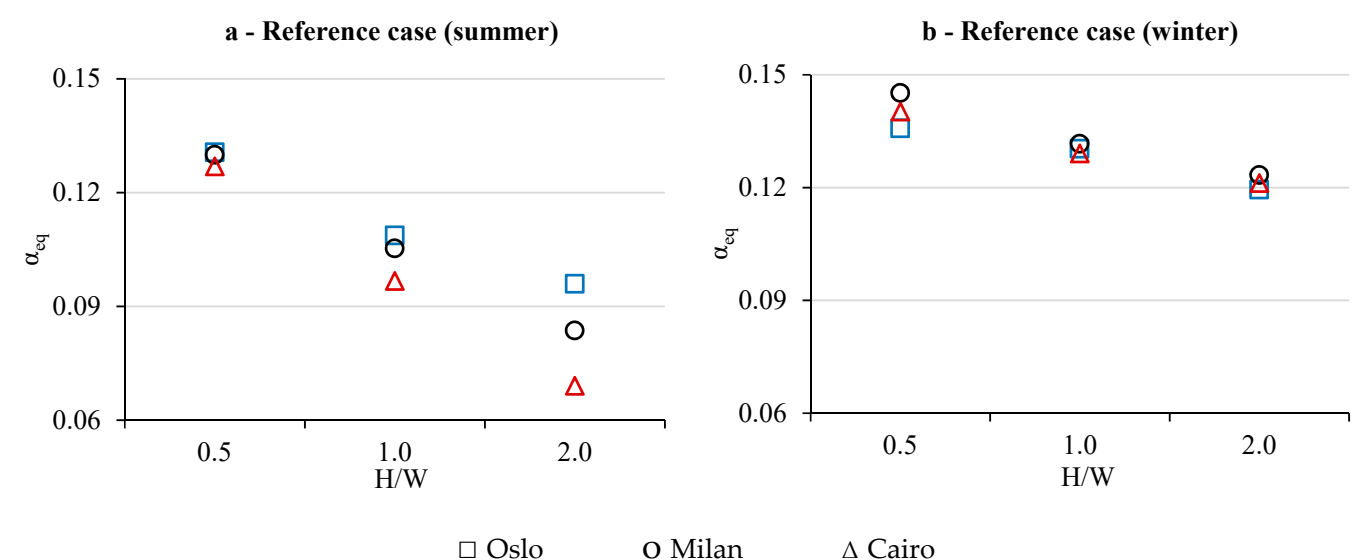

Figure 8. Equivalent albedo estimated in summer (a) and in winter (b), depending on the latitude and UC aspect ratio.

\subsection{Influences of Optimized Cool Materials on Urban Equivalent Albedo}

In the northern zone, retro-reflective (case a) or angular-selective retro-reflective coatings (case $b$ ) added to the street surface allowed for an improvement of the equivalent albedo (Figure 9). During the summer, $\alpha_{\text {eq }}$ was increased by percentages ranging from $14 \%(\mathrm{H} / \mathrm{W}=2.0)$ to $73 \%(\mathrm{H} / \mathrm{W}=0.5)$ for case $\mathrm{a}$, and from $7 \%(\mathrm{H} / \mathrm{W}=2.0)$ to $66 \%(\mathrm{H} / \mathrm{W}=0.5)$ for case $\mathrm{b}$. In winter, the influences of the finishing cool materials applied to the street surface were negligible in the high-density configuration $(\mathrm{H} / \mathrm{W}=2.0)$ when a selective behavior was implemented (case b). Conversely, the UC enhanced with an RR street showed a $27 \%$ increment in the $\alpha_{\mathrm{eq}}$ for the same UC geometry.

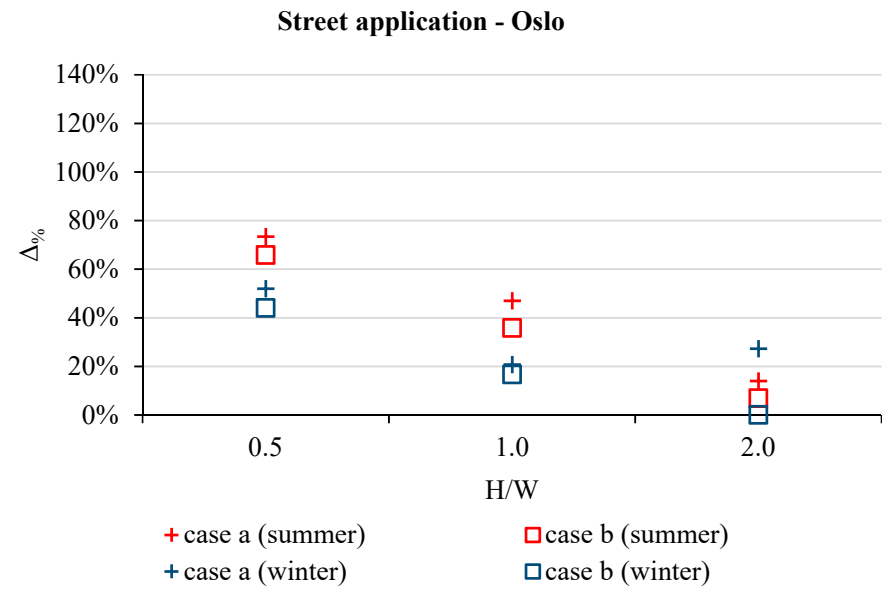

Figure 9. Estimated $\Delta \%$,sum and $\Delta \%$,win values when RR (case a) or AS-RR (case b) materials are applied to the street, in the northern zone.

It is worth highlighting that the $\Delta \%$,win values estimated for case a were not proportional to the UC aspect ratio. The reason for this is the low solar irradiation amounts estimated for the Oslo latitude during winter. In fact, the accuracy of the Monte Carlo-based numerical model was reduced when it came to such small quantities and the outcomes were considered as qualitative. Thus, reasonably, $\Delta \%$,win was also proportional to $\mathrm{H} / \mathrm{W}$ as observed in the other configurations.

When it came to case $c$ and case $\mathrm{d}$ (RR and AS-RR materials applied to the southexposed façade), $\alpha_{\text {eq }}$ calculated for the Oslo latitude was increased more in summer than in winter (Figure 10). In particular, the increment of $\alpha_{\mathrm{eq}}$ varied from $18 \%(\mathrm{H} / \mathrm{W}=0.5)$ to $73 \%(\mathrm{H} / \mathrm{W}=2.0)$ for case $\mathrm{c}$, and from $12 \%(\mathrm{H} / \mathrm{W}=0.5)$ to $41 \%(\mathrm{H} / \mathrm{W}=2.0)$ for case $\mathrm{d}$, during the summer. In winter, $\Delta \%$,win seemed to be unaffected by changes in the density pattern, and it was estimated to be equal to around $25 \%$ for case c. Conversely, such an increase in $\alpha_{\text {eq }}$ ranged from $4 \%$ to $18 \%$ for case $d$, during the winter. As observed in case 
a, the $\Delta \%$,win values calculated for case $\mathrm{d}$ were not proportional to the UC aspect ratio. The reason is the same as above and it is due to the reduced accuracy of the numerical model when assessing such weather conditions (winter season in Oslo).

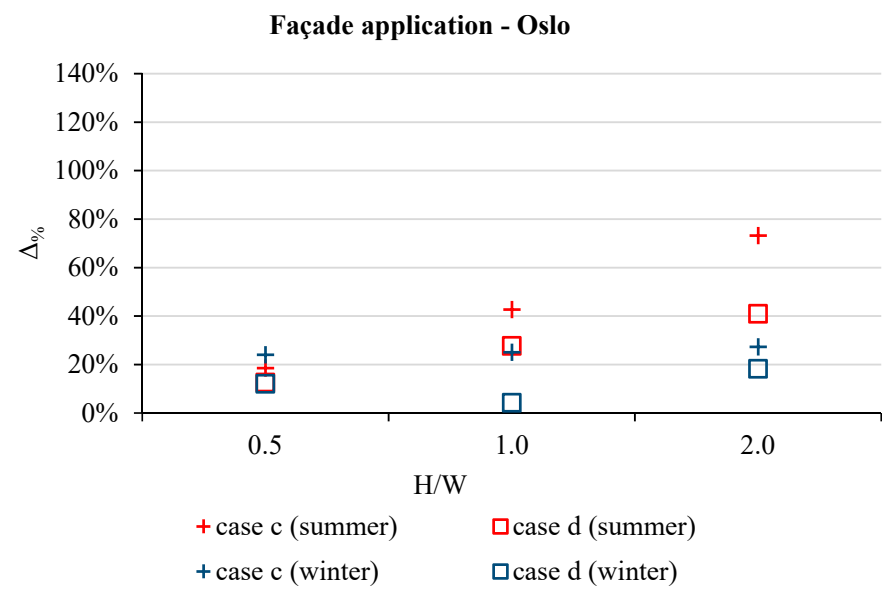

Figure 10. Estimated $\Delta \%$,sum and $\Delta \%$,win values when RR (case c) or AS-RR (case d) materials are applied to the most irradiated façade, in the northern zone.

In the central zone, the finishing cool materials used on the street paving (case a and case b) contributed to boosting the $\alpha_{\text {eq }}$ of the urban canyon (Figure 11). During the summer, $\Delta \%$,sum calculated for case a and for case b varied from $43 \%(\mathrm{H} / \mathrm{W}=2.0)$ to $84 \%(\mathrm{H} / \mathrm{W}=0.5)$, and from $18 \%(\mathrm{H} / \mathrm{W}=2.0)$ to $68 \%(\mathrm{H} / \mathrm{W}=0.5)$, respectively. The same trends were observed in winter, when $\alpha_{\text {eq }}$ turned out to be increased by a percentage ranging from $11 \%$ $(\mathrm{H} / \mathrm{W}=2.0)$ to $37 \%(\mathrm{H} / \mathrm{W}=0.5)$ for case $\mathrm{a}$, and from $4 \%(\mathrm{H} / \mathrm{W}=2.0)$ to $33 \%(\mathrm{H} / \mathrm{W}=0.5)$ for case $b$. Implementing a retro-reflective behavior on the street surface was found to be more effective in low-density UCs when the solar accessibility of the street is maximum.

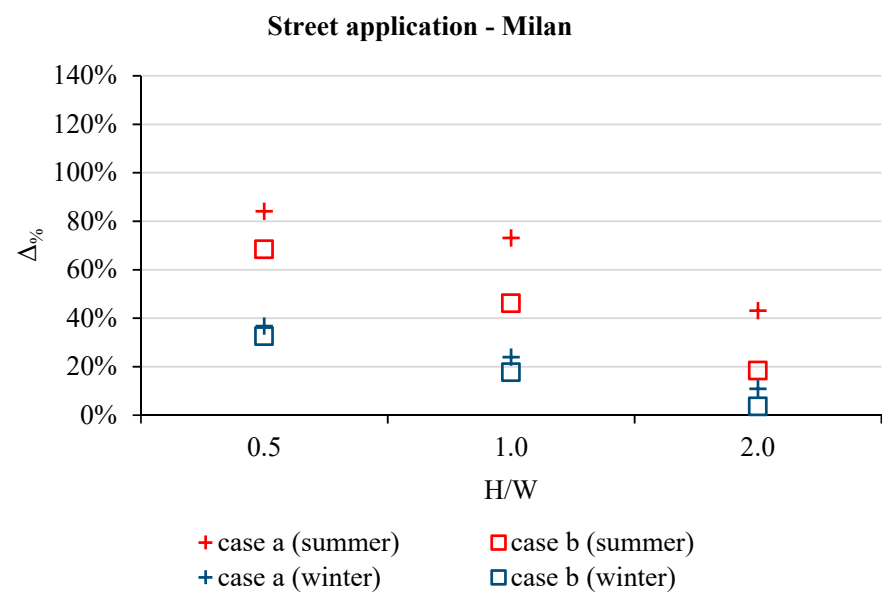

Figure 11. Estimated $\Delta \%$,sum and $\Delta \%$,win values when RR (case a) or AS-RR (case b) materials are applied to the street, in the central zone.

When it came to the façade application in Milan, RR and AS-RR materials showed the same effectiveness in increasing the $\alpha_{\text {eq }}$ of the various UC scenarios (except for the high-density pattern), in summer (Figure 12). In fact, the $\Delta_{\% \text {,sum quantities estimated for }}$ case $\mathrm{c}$ and case $\mathrm{d}$ were respectively equal to $11 \%$ and $8 \%$ (for $0.5 \mathrm{H} / \mathrm{W}$ ), $25 \%$ and $20 \%$ (for $1.0 \mathrm{H} / \mathrm{W}$ ), and $47 \%$ and $62 \%$ (for $2.0 \mathrm{H} / \mathrm{W}$ ). During the winter, the RR façade was capable of increasing the $\alpha_{\mathrm{eq}}$ by up to $39 \%(\mathrm{H} / \mathrm{W}=2.0)$, while the AS-RR materials only improved this by up to $21 \%(\mathrm{H} / \mathrm{W}=2.0)$. Differently from the street applications (case a and case $\mathrm{b}$ ), RR and AS-RR façades were more effective in high-density UCs where most of the solar irradiation entering the domain was incident on the buildings' façades. 


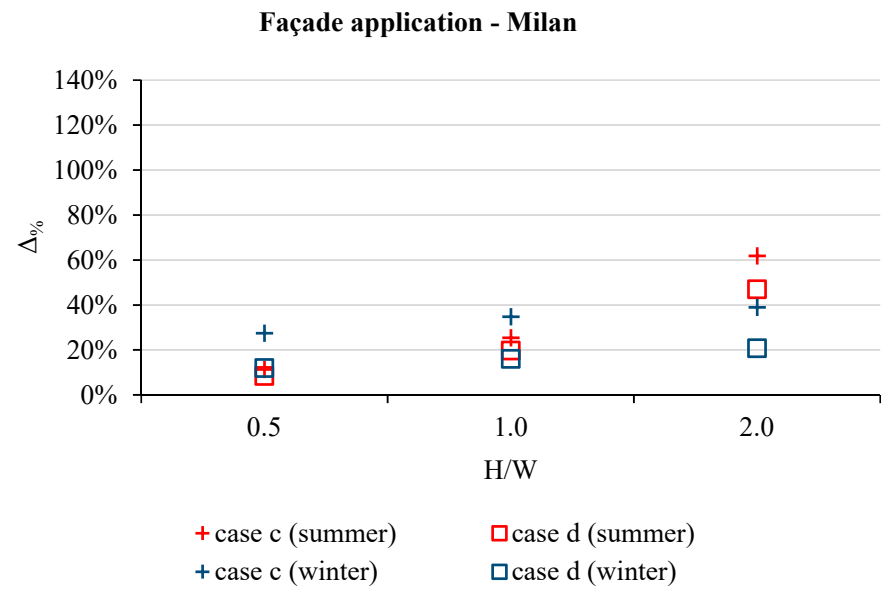

Figure 12. Estimated $\Delta \%$,sum and $\Delta \%$,win values when RR (case c) or AS-RR (case d) materials were applied to the most irradiated façade, in the central zone.

In the southern zone, the angular range of activation of RR properties, which was defined by Manni et al. [38], for the horizontal surfaces ranged from $0^{\circ}$ to $90^{\circ}$ so the case $a$ and case $b$ scenarios are the same. Therefore, the following outcomes will refer to both scenarios. The $\alpha_{\text {eq }}$ was increased by more than $100 \%$ in every density pattern (up to $122 \%$ in the case of $2.0 \mathrm{H} / \mathrm{W}$ ), during the summer (Figure 13). In winter, the $\Delta \%$,win decreased when the $\mathrm{H} / \mathrm{W}$ increased: it ranged from $7 \%(\mathrm{H} / \mathrm{W}=2.0)$ to $44 \%(\mathrm{H} / \mathrm{W}=0.5)$. It is worth highlighting that differently from the Oslo and Milan latitudes, cool materials applied to the street were more effective in the high-density UC in Cairo.

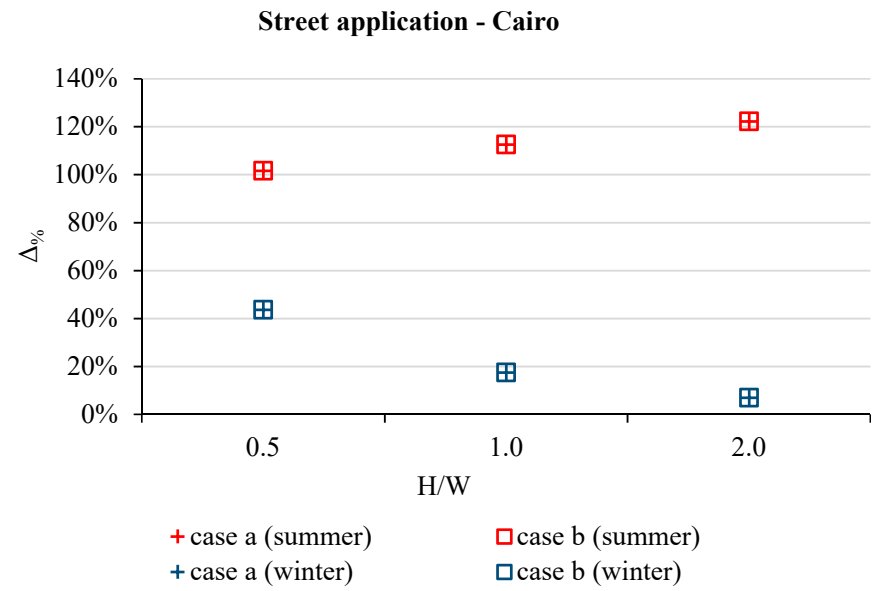

Figure 13. Estimated $\Delta \%$,sum and $\Delta \%$,win values when RR (case a) or AS-RR (case b) materials were applied to the street, in the southern zone.

When applied to the south-exposed façade in Cairo, the finishing cool materials showed their best performances in winter (Figure 14). This was due to the fact that sunrays were almost vertical in the summer, and they were mainly incident on the street, which was characterized by a higher solar absorptivity. During the summer, the equivalent albedo was increased by a percentage varying between $3 \%(\mathrm{H} / \mathrm{W}=0.5)$ and $15 \%(\mathrm{H} / \mathrm{W}=2.0)$ for case $\mathrm{c}$, and between $2 \%(\mathrm{H} / \mathrm{W}=0.5)$ and $9 \%(\mathrm{H} / \mathrm{W}=2.0)$ for case $\mathrm{d}$. In winter, $\mathrm{RR}$ materials were as effective as the AS-RR materials, and the $\Delta \%$,win values turned out to be equal to around $27 \%(\mathrm{H} / \mathrm{W}=0.5), 43 \%(\mathrm{H} / \mathrm{W}=1.0)$, and $47 \%(\mathrm{H} / \mathrm{W}=2.0)$. 


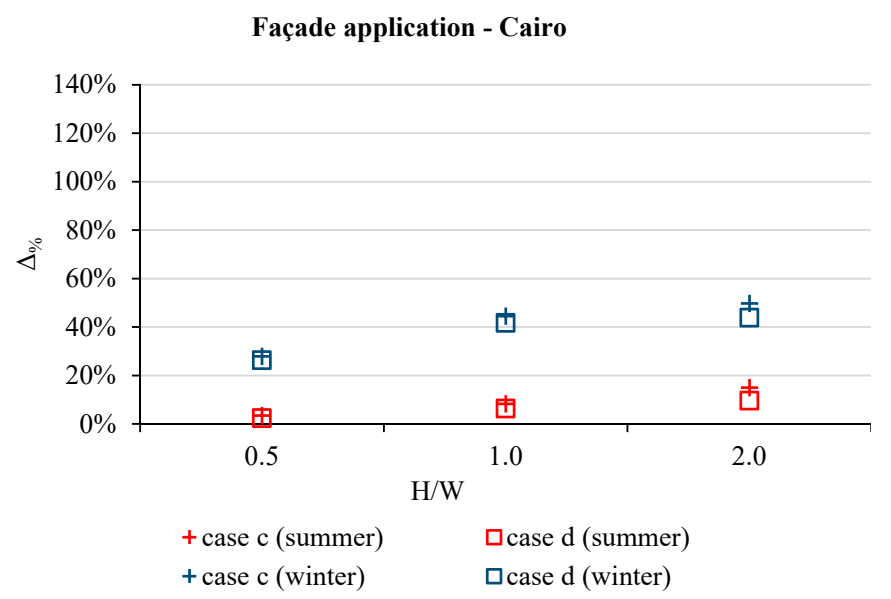

Figure 14. Estimated $\Delta \%$,sum and $\Delta \%$,win values when RR (case c) or AS-RR (case d) materials are applied to the most irradiated façade, in the southern zone.

\subsection{Guidelines about the Exploitation of RR and AS-RR Materials}

The analyses of the results (Table 3) permitted identification of guidelines regarding RR and AS-RR materials applied either to the street or to the façade.

Table 3. Equivalent albedo values estimated for each configuration assessed in the summer and in the winter.

\begin{tabular}{|c|c|c|c|c|c|c|c|c|c|}
\hline \multicolumn{10}{|c|}{21 June. } \\
\hline & \multicolumn{3}{|c|}{ Oslo } & \multicolumn{3}{|c|}{ Milan } & \multicolumn{3}{|c|}{ Cairo } \\
\hline & $\mathrm{H} / \mathrm{W}=0.5$ & $\mathrm{H} / \mathrm{W}=1.0$ & $\mathrm{H} / \mathrm{W}=\mathbf{2 . 0}$ & $\mathrm{H} / \mathrm{W}=0.5$ & $\mathrm{H} / \mathrm{W}=1.0$ & $\mathrm{H} / \mathrm{W}=\mathbf{2 . 0}$ & $\mathrm{H} / \mathrm{W}=0.5$ & $\mathrm{H} / \mathrm{W}=1.0$ & $\mathrm{H} / \mathrm{W}=\mathbf{2 . 0}$ \\
\hline case a & $73 \%$ & $47 \%$ & $14 \%$ & $84 \%$ & $73 \%$ & $43 \%$ & $102 \%$ & $113 \%$ & $122 \%$ \\
\hline case $\mathbf{b}$ & $66 \%$ & $36 \%$ & $7 \%$ & $68 \%$ & $46 \%$ & $18 \%$ & $102 \%$ & $113 \%$ & $122 \%$ \\
\hline case $\mathrm{c}$ & $18 \%$ & $43 \%$ & $73 \%$ & $11 \%$ & $25 \%$ & $35 \%$ & $3 \%$ & $8 \%$ & $15 \%$ \\
\hline case $\mathrm{d}$ & $12 \%$ & $28 \%$ & $41 \%$ & $8 \%$ & $20 \%$ & $16 \%$ & $2 \%$ & $6 \%$ & $9 \%$ \\
\hline \multicolumn{10}{|c|}{21 December } \\
\hline & \multicolumn{3}{|c|}{ Oslo } & \multicolumn{3}{|c|}{ Milan } & \multicolumn{3}{|c|}{ Cairo } \\
\hline & $\mathrm{H} / \mathrm{W}=0.5$ & $\mathrm{H} / \mathrm{W}=1.0$ & $\mathrm{H} / \mathrm{W}=\mathbf{2 . 0}$ & $\mathrm{H} / \mathrm{W}=0.5$ & $\mathrm{H} / \mathrm{W}=1.0$ & $\mathrm{H} / \mathrm{W}=2.0$ & $\mathrm{H} / \mathrm{W}=0.5$ & $\mathrm{H} / \mathrm{W}=1.0$ & $\mathrm{H} / \mathrm{W}=2.0$ \\
\hline case a & $52 \%$ & $21 \%$ & $27 \%$ & $37 \%$ & $24 \%$ & $11 \%$ & $44 \%$ & $18 \%$ & $7 \%$ \\
\hline case $\mathbf{b}$ & $44 \%$ & $17 \%$ & - & $33 \%$ & $18 \%$ & $4 \%$ & $44 \%$ & $18 \%$ & $7 \%$ \\
\hline case $\mathrm{c}$ & $24 \%$ & $25 \%$ & $27 \%$ & $27 \%$ & $35 \%$ & $39 \%$ & $28 \%$ & $44 \%$ & $50 \%$ \\
\hline case $\mathrm{d}$ & $12 \%$ & $4 \%$ & $18 \%$ & $12 \%$ & $16 \%$ & $21 \%$ & $26 \%$ & $42 \%$ & $44 \%$ \\
\hline
\end{tabular}

Finishing cool materials applied to the street paving increased the UC equivalent albedo in a way that is inversely proportional to the UC aspect ratio (except for the northern zone in winter and the southern zone in summer). The investigated cool coatings were effective in increasing the equivalent albedo in the southern zone. It has to be highlighted that the solar reflectance of the street (higher than in the reference case) played a significant role in that regard.

The following guidelines can be carried out for the street application:

- $\quad$ RR and AS-RR materials can be applied to the street surface to increase $\alpha_{\text {eq; }}$;

- $\quad$ RR and AS-RR materials achieve a higher performance in summer than in winter;

- $\quad$ RR and AS-RR materials are more effective in low-density $(\mathrm{H} / \mathrm{W} \leq 0.5)$ urban environments.

The use of finishing cool materials on the south façade demonstrated that they allow an increase of the UC equivalent albedo throughout the year. Differently from the street 
application, their effectiveness was directly proportional to the UC aspect ratio and the highest performance levels were observed in the northern zone.

The following guidelines can be carried out for the façade application:

- $\quad$ RR and AS-RR materials can be exploited on south-exposed façades to increase $\alpha_{\text {eq; }}$;

- $\quad$ RR and AS-RR materials should be exploited in the central and in southern zones with the aim of increasing $\alpha_{\mathrm{eq}}$ during winter;

- Utilizing RR and AS-RR materials should be considered in a high-density ( $\mathrm{H} / \mathrm{W} \geq 2.0)$ urban environment.

\subsection{Limitations}

The main limitations of the study are reported and discussed in this section. Firstly, the utilization of data about solar irradiation from statistic-based weather data files may result in incorrect computing of diffuse fractions as well as in systematic error within the evaluation of the potential benefits. Such types of weather data files are, however, the usual source of weather data in the preliminary phase of the design process, and are today the most used and most accepted source of weather data inputs used in building performance simulation.

Secondly, the Monte Carlo-based numerical model has reduced accuracy when it comes to the evaluation of low solar irradiation amounts. This was particularly evident in the analyses carried out for Oslo case study, during the winter. Such a limitation can be accepted during the early stage of the design process when results are considered as qualitative, and conclusions are general.

\section{Conclusions}

The results highlighted that RR and AS-RR materials show different impacts depending on the surfaces to which they are applied. When exploited as cool street pavements, RR materials were capable of increasing the equivalent albedo particularly in summer. Implementing an angular-selective behavior led to worsening of the materials' effectiveness throughout the year, but it enabled lower $\Delta \%$,win (if compared to the scenarios enhanced with RR materials). The application of RR coatings to the south-exposed façade similarly caused an increase of the urban equivalent albedo. The angular-selective behavior of the RR properties that was implemented in the AS-RR materials allowed a reduction of the mitigation potential of cool coatings during the winter season in the northern and central zones, and during summer in the southern zone.

The main findings of this study can be summarized as follows:

- Street surfaces treated with RR and AS-RR materials affect the urban equivalent albedo in the same way, although with different magnitudes;

- In their best street application (high-density UC in Cairo, southern zone), AS-RR materials can increase the $\alpha_{\mathrm{eq}}$ by $122 \%$ in summer and by $7 \%$ in winter;

- South façades treated with RR and AS-RR materials can reduce the equivalent albedo by the same percentage in the northern and central zones;

- In their best façade application (high-density UC in Oslo, northern zone), optimized cool materials can increase the $\alpha_{\text {eq }}$ by $73 \%$ in summer and by $41 \%$ in winter.

In conclusion, the performed solar analyses demonstrated the effectiveness of optimized cool coatings to improve the equivalent albedo of street corridors. However, further analyses are needed to evaluate the comprehensive effects of such materials by relating their impact on the microclimate to both indoor and outdoor users' thermal comfort. Alongside this, it is necessary to assess the effects of weathering on materials' optical properties [48] as well as to investigate and optimize costs and benefits by following an approach similar to the one proposed by Saafi and Daouas [49].

As far as further development of optimized cool materials is concerned, future trends may include an investigation of technology solutions to implement a selective behavior that is alternative to the angular-selective properties proposed in the AS-RR materials. In this regard, the possibility of coupling a retro-reflective layer to a thermochromic substrate could 
be explored. Hence, the retro-reflection would be activated whenever the thermochromics' transition temperature threshold is overpassed.

Author Contributions: Conceptualization, M.M. and A.N.; methodology, A.N.; software, M.M.; validation, M.M. and A.N.; formal analysis, M.M.; investigation, M.M.; resources, A.N.; data curation, M.M.; writing—original draft preparation, M.M.; writing—review and editing, A.N.; visualization, M.M.; supervision, A.N.; project administration, A.N.; funding acquisition, A.N. Writing—original draft, M.M.; Writing - review and editing, A.N. All authors have read and agreed to the published version of the manuscript.

Funding: This research received no external funding.

Institutional Review Board Statement: Not applicable.

Informed Consent Statement: Not applicable.

Conflicts of Interest: The authors declare no conflict of interest.

\section{References}

1. Warren, C.M.J. Heat Islands; Understanding and Mitigating Heat in Urban Areas. Prop. Manag. 2014, 30, 105-106. [CrossRef]

2. Oke, T.R. Canyon geometry and the nocturnal urban heat island: Comparison of scale model and field observations. J. Climatol. 1981, 1, 237-254. [CrossRef]

3. Xie, X.; Huang, Z.; Wang, J.; Xie, Z. The impact of solar radiation and street layout on pollutant dispersion in street canyon. Build. Environ. 2005, 40, 201-212. [CrossRef]

4. Piselli, C.; Castaldo, V.L.; Pigliautile, I.; Pisello, A.L.; Cotana, F. Outdoor comfort conditions in urban areas: On citizens' perspective about microclimate mitigation of urban transit areas. Sustain. Cities Soc. 2018, 39, 16-36. [CrossRef]

5. Kohler, M.; Blond, N.; Clappier, A. A city scale degree-day method to assess building space heating energy demands in Strasbourg Eurometropolis (France). Appl. Energy 2016, 184, 40-54. [CrossRef]

6. Schrijvers, P.J.C.; Jonker, H.J.J.; de Roode, S.R.; Kenjereš, S. The effect of using a high-albedo material on the Universal Temperature Climate Index within a street canyon. Urban Clim. 2016, 17, 284-303. [CrossRef]

7. Wang, Y.; Akbari, H. Analysis of urban heat island phenomenon and mitigation solutions evaluation for Montreal. Sustain. Cities Soc. 2016, 26, 438-446. [CrossRef]

8. Pyrgou, A.; Castaldo, V.L.; Pisello, A.L.; Cotana, F.; Santamouris, M. On the effect of summer heatwaves and urban overheating on building thermal-energy performance in central Italy. Sustain. Cities Soc. 2017, 28, 187-200. [CrossRef]

9. Palme, M.; Inostroza, L.; Villacreses, G.; Lobato-Cordero, A.; Carrasco, C. From urban climate to energy consumption. Enhancing building performance simulation by including the urban heat island effect. Energy Build. 2017, 145, 107-120. [CrossRef]

10. Santamouris, M. Analyzing the heat island magnitude and characteristics in one hundred Asian and Australian cities and regions. Sci. Total Environ. 2015, 512-513, 582-598. [CrossRef]

11. Founda, D.; Santamouris, M. Synergies between Urban Heat Island and Heat Waves in Athens (Greece), during an extremely hot summer (2012). Sci. Rep. 2017, 7, 10973. [CrossRef] [PubMed]

12. Santamouris, M.; Feng, J. Recent progress in daytime radiative cooling: Is it the air conditioner of the future? Buildings 2018, 8, 168. [CrossRef]

13. Santamouris, M. Regulating the damaged thermostat of the cities-Status, impacts and mitigation challenges. Energy Build. 2015, 91, 43-56. [CrossRef]

14. Santamouris, M. Heat Island Research in Europe: The State of the Art. Adv. Build. Energy Res. 2007, 1, 123-150. [CrossRef]

15. Lima, I.; Scalco, V.; Lamberts, R. Estimating the impact of urban densification on high-rise office building cooling loads in a hot and humid climate. Energy Build. 2019, 182, 30-44. [CrossRef]

16. Akbari, H.; Kolokotsa, D. Three decades of urban heat islands and mitigation technologies research. Energy Build. 2016, 133, 834-842. [CrossRef]

17. Brans, K.I.; Engelen, J.M.T.; Souffreau, C.; De Meester, L. Urban hot-tubs: Local urbanization has profound effects on average and extreme temperatures in ponds. Landsc. Urban Plan. 2018, 176, 22-29. [CrossRef]

18. Lin, L.; Ge, E.; Liu, X.; Liao, W.; Luo, M. Urbanization effects on heat waves in Fujian Province, Southeast China. Atmos. Res. 2018, 210, 123-132. [CrossRef]

19. Santamouris, M. Energy and Climate in the Urban Built Environment; Routledge: London, UK, 2001; ISBN 9781315073774.

20. Grilo, F.; Pinho, P.; Aleixo, C.; Catita, C.; Silva, P.; Lopes, N.; Freitas, C.; Santos-Reis, M.; McPhearson, T.; Branquinho, C. Using green to cool the grey: Modelling the cooling effect of green spaces with a high spatial resolution. Sci. Total Environ. 2020, 724, 138182. [CrossRef]

21. Ziaul, S.; Pal, S. Modeling the effects of green alternative on heat island mitigation of a meso level town, West Bengal, India. Adv. Sp. Res. 2020, 65, 1789-1802. [CrossRef]

22. Battista, G.; de Lieto Vollaro, R.; Zinzi, M. Assessment of urban overheating mitigation strategies in a square in Rome, Italy. Sol. Energy 2019, 180, 608-621. [CrossRef] 
23. Piselli, C.; Castaldo, V.L.; Pisello, A.L. How to enhance thermal energy storage effect of PCM in roofs with varying solar reflectance: Experimental and numerical assessment of a new roof system for passive cooling in different climate conditions. Sol. Energy 2019, 192, 106-119. [CrossRef]

24. Kousis, I.; Fabiani, C.; Gobbi, L.; Pisello, A.L. Phosphorescent-based pavements for counteracting urban overheating-A proof of concept. Sol. Energy 2020, 202, 540-552. [CrossRef]

25. Liu, N.; Morawska, L. Modeling the urban heat island mitigation effect of cool coatings in realistic urban morphology. J. Clean. Prod. 2020, 264, 121560. [CrossRef]

26. Manni, M.; Petrozzi, A.; Coccia, V.; Nicolini, A.; Cotana, F. Investigating alternative development strategies for sport arenas based on active and passive systems. J. Build. Eng. 2020, 31, 101340. [CrossRef]

27. Santamouris, M.; Yun, G.Y. Recent development and research priorities on cool and super cool materials to mitigate urban heat island. Renew. Energy 2020, 161, 792-807. [CrossRef]

28. Jandaghian, Z.; Berardi, U. Analysis of the cooling effects of higher albedo surfaces during heat waves coupling the Weather Research and Forecasting model with building energy models. Energy Build. 2020, 207, 109627. [CrossRef]

29. Nazarian, N.; Dumas, N.; Kleissl, J.; Norford, L. Effectiveness of cool walls on cooling load and urban temperature in a tropical climate. Energy Build. 2019, 187, 144-162. [CrossRef]

30. Tsoka, S.; Theodosiou, T.; Tsikaloudaki, K.; Flourentzou, F. Modeling the performance of cool pavements and the effect of their aging on outdoor surface and air temperatures. Sustain. Cities Soc. 2018, 42, 276-288. [CrossRef]

31. Wang, C.; Wang, Z.H.; Kaloush, K.E.; Shacat, J. Cool pavements for urban heat island mitigation: A synthetic review. Renew. Sustain. Energy Rev. 2021, 146, 111171. [CrossRef]

32. Rossi, F.; Pisello, A.L.; Nicolini, A.; Filipponi, M.; Palombo, M. Analysis of retro-reflective surfaces for urban heat island mitigation: A new analytical model. Appl. Energy 2014, 114, 621-631. [CrossRef]

33. Morini, E.; Castellani, B.; Presciutti, A.; Filipponi, M.; Nicolini, A.; Rossi, F. Optic-energy performance improvement of exterior paints for buildings. Energy Build. 2017, 139, 690-701. [CrossRef]

34. Yuan, J.; Emura, K.; Farnham, C. Potential for Application of Retroreflective Materials instead of Highly Reflective Materials for Urban Heat Island Mitigation. Urban Stud. Res. 2016, 2016, 626294. [CrossRef]

35. Sakai, H.; Emura, K.; Igawa, N. Reduction of reflected heat by retroreflective materilas. J. Struct. Constr. Eng. (Trans. AIJ) 2008, 73, 1239-1244. [CrossRef]

36. Han, Y.; Taylor, J.E.; Pisello, A.L. Toward Mitigating Urban Heat Island Effects: Investigating the Thermal-Energy Impact of Bio-Inspired Retro-reflective Building Envelopes in Dense Urban Settings. Energy Build. 2015, 102, 380-389. [CrossRef]

37. Sakai, H.; Iyota, H. Development of Two New Types of Retroreflective Materials as Countermeasures to Urban Heat Islands. Int. J. Thermophys. 2017, 38, 131-141. [CrossRef]

38. Manni, M.; Lobaccaro, G.; Goia, F.; Nicolini, A. An inverse approach to identify selective angular properties of retro-reflective materials for urban heat island mitigation. Sol. Energy 2018, 176, 194-210. [CrossRef]

39. Manni, M.; Bonamente, E.; Lobaccaro, G.; Goia, F.; Nicolini, A.; Bozonnet, E.; Rossi, F. Development and validation of a Monte Carlo-based numerical model for solar analyses in urban canyon configurations. Build. Environ. 2020, 170, 106638. [CrossRef]

40. Manni, M.; Cardinali, M.; Lobaccaro, G.; Goia, F.; Nicolini, A.; Rossi, F. Effects of retro-reflective and angular-selective retroreflective materials on solar energy in urban canyons. Sol. Energy 2020, 209, 662-673. [CrossRef]

41. Lobaccaro, G.; Wiberg, A.H.; Ceci, G.; Manni, M.; Lolli, N.; Berardi, U. Parametric design to minimize the embodied GHG emissions in a ZEB. Energy Build. 2018, 167, 106-123. [CrossRef]

42. Manni, M.; Lobaccaro, G.; Goia, F.; Nicolini, A.; Rossi, F. Exploiting selective angular properties of retro-reflective coatings to mitigate solar irradiation within the urban canyon. Sol. Energy 2019, 189, 74-85. [CrossRef]

43. Martilli, A.; Clappier, A.; Rotach, M.W. An Urban Surface Exchange Parameterisation for Mesoscale Models. Bound.-Layer Meteorol. 2002, 104, 261-304. [CrossRef]

44. Masson, V. A Physically-Based Scheme For The Urban Energy Budget In Atmospheric Models. Bound.-Layer Meteorol. 2000, 94, 357-397. [CrossRef]

45. Kusaka, H.; Kondo, H.; Kikegawa, Y.; Kimura, F. A Simple Single-Layer Urban Canopy Model For Atmospheric Models: Comparison With Multi-Layer And Slab Models. Bound.-Layer Meteorol. 2001, 101, 329-358. [CrossRef]

46. Wang, Z.-H.; Bou-Zeid, E.; Smith, J.A. A coupled energy transport and hydrological model for urban canopies evaluated using a wireless sensor network. Q. J. R. Meteorol. Soc. 2013, 139, 1643-1657. [CrossRef]

47. Castellani, B.; Morini, E.; Anderini, E.; Filipponi, M.; Rossi, F. Development and characterization of retro-reflective colored tiles for advanced building skins. Energy Build. 2017, 154, 513-522. [CrossRef]

48. Xie, N.; Li, H.; Zhang, H.; Zhang, X.; Jia, M. Effects of accelerated weathering on the optical characteristics of reflective coatings for cool pavement. Sol. Energy Mater. Sol. Cells 2020, 215, 110698. [CrossRef]

49. Saafi, K.; Daouas, N. A life-cycle cost analysis for an optimum combination of cool coating and thermal insulation of residential building roofs in Tunisia. Energy 2018, 152, 925-938. [CrossRef] 